\title{
Fractal and stereological analyses of insulin- -induced rat exocrine pancreas remodelling
}

\author{
M. Pajevic ${ }^{1}$, M. Aleksic ${ }^{2}$, I. Golic ${ }^{2}$, M. Markelic ${ }^{2}$, V. Otasevic ${ }^{3}$ A. Jankovic ${ }^{3}$, A. Stancic ${ }^{3}$, \\ B. Korac ${ }^{3}$, A. Korac ${ }^{2}$ \\ ${ }^{1}$ Department of Histopathology, Clinical Centre of Serbia, Belgrade, Serbia \\ ${ }^{2}$ Center for Electron Microscopy, University of Belgrade, Faculty of Biology, Belgrade, Serbia \\ 3Institute for Biological Research "Sinisa Stankovic", University of Belgrade, Belgrade, Serbia
}

[Received: 20 September 2017; Accepted: 28 October 2017]

\begin{abstract}
Background: The effect of insulin on the endocrine pancreas has been the subject of extensive study, but quantitative morphometric investigations of the exocrine pancreas are scarce. This study was therefore undertaken to investigate the effect of acute and chronic insulin administration (two doses, $0.4 \mathrm{IU}$ and $4 \mathrm{IU}$ ) on the morphology of rat pancreas acini.
\end{abstract}

Materials and methods: Semi-fine sections stained with methylene blue and basic fuchsine or haematoxylin and eosin-stained 5-micrometer thick paraffin sections were used for fractal and stereological analysis of exocrine acini. Acute insulin treatment, independent of applied doses increased fractal dimension in line with decreased lacunarity of pancreas acini. Chronic low dose insulin decreased fractal dimension and increased lacunarity of pancreas acini, but a high dose had the opposite effect. The volume densities (VV) of cytoplasm, granules and nucleus are affected differently: acute low dose and high chronic dose significantly decreased granules $V V$, and in line increased cytoplasmic $V$, whereas other examined structures showed slight changes without statistical significance.

Results: The results obtained from this investigation indicate that insulin treatment induced structural remodelling of the exocrine pancreas suggesting a substantial role of insulin in its functioning.

Conclusions: Additionally, we showed that fine architectural changes in acini could be detected by fractal analysis, suggesting this method as an alternative or addition to routine stereology. (Folia Morphol 2018; 77, 3: 478-484)

Key words: insulin, pancreas acini, fractal analysis, stereology

\section{INTRODUCTION}

Pancreas complexity is reflected by both histological organisation and function. While the exocrine portion comprises more than $95 \%$ of the pancreas, the endocrine portion represents a diffuse organ composed of islets of Langerhans dispersed between exocrine pancreatic acini. Both parts are equally active in digestion and metabolism through secretion of digestive enzymes from the exocrine portion and hormones from the endocrine portion. A close morphological relationship allows functional interactions, but the mechanisms of active crosstalk between the exocrine and endocrine pancreas are not entirely resolved. It is known that the relationship between the endocrine and exocrine pancreas is mediated by islet-derived hormones and neurotransmitters [5, 23]. Among islet-derived hormones, insulin most likely has a leading role. 
Insulin has diverse biological effects, although it is best known for its regulatory role in glucose and lipid metabolism, protein synthesis and cell growth, division and survival [27]. The conclusions drawn from the experiments on laboratory animals have revealed that insulin has trophic and secretory effects on the exocrine pancreas. Early anatomic studies indicate the presence of a portal system that conveys islet blood to acinar cells $[3,5,37]$. Digestive enzymes are stored in the zymogen granule of acinar cells, and their release occurs through exocytosis stimulated by neurohumoural agents, including exogenous and endogenous insulin [23].

In addition, a number of studies have indicated the existence of direct (via acinar insulin receptors) and indirect (influence on cholecystokinin mechanisms) effects of insulin on acinar cells. The pancreatic acinar cells have specific high-affinity receptors for insulin that are involved in regulation of digestive enzyme synthesis and the number of cholecystokinin receptors. Additionally, exogenous insulin is believed to act as a trophic factor to maintaining the amylase level in acini $[4,21,38]$. As a consequence of the close anatomical and functional links between the exocrine and endocrine pancreas, any disturbance affecting one of these parts will inevitably affect the other. The development of severe diseases of the exocrine pancreas is associated with structural abnormalities of the islets, which contribute to functional changes that may extend to impaired hormone-secretory capacity $[4,14,25,28]$.

Insulin resistance is defined as a condition of reduced metabolic response of a target cell or a whole organism to the normal insulin concentration. Insulin resistance and its metabolic consequences including compensatory hyperinsulinaemia represent a link to cluster of metabolic abnormalities termed the metabolic syndrome or syndrome $X$ (hypertension, type 2 diabetes, dyslipidaemia, coronary artery disease, obesity, abnormal glucose tolerance) $[2,10,11,29,30,36]$.

Numerous studies have investigated the influence of insulin on the physiological processes, secretion and receptor distribution in tissues $[14,20,39]$. However, insulin effect on exocrine pancreas tissue architecture still remains unknown.

During the past 20 years, the fractal concept has improved our understanding of many appearances in biological systems. Fractal analysis is a well-established method for the quantification of geometrical complexity in biological and biophysical systems $[15,22,35]$. It is widely applied to investigate the metabolic rate, population genetics, tissue organisation and tumour growth.
Recent studies have shown that computerised analysis of microscopic images is an objective and reproducible method for diagnostic and prognostic purposes $[1,6,12,13]$. Fractal analysis allows for the detection of subtle morphologic changes. The fractal dimension is able to transduce shape complexity in analytical quantitative data, harmonising the gap between structural features and functional quantitative measures. Fractal dimension is a measure of geometrical complexity of the tissue, while lacunarity is a measure of tissue homogeneity $[24,31]$.

The present study was designed to provide a detailed description of insulin effects on the exocrine pancreas morphology using stereology and fractal analysis.

\section{MATERIALS AND METHODS}

\section{Animals and experimental design}

All procedures performed in this experiment were approved by the Ethics Committee for the Treatment of Experimental Animals (Faculty of Biology, University of Belgrade, Serbia). Two-month-old Wistar male rats $(190-260 \mathrm{~g})$ were maintained under $22 \pm 1{ }^{\circ} \mathrm{C}$ and $12 \mathrm{~h}$ light/dark cycles with ad libitum access to standard pelleted food and water. They were divided into six groups each consisting of six animals. The first four groups were treated acutely (1 day) or chronically (3 days) with low $(0.4 \mathrm{lU} / \mathrm{kg})$ or high $(4 \mathrm{IU} / \mathrm{kg}$, one intraperitoneal injection per day) doses of insulin (Mixtard ${ }^{\circledR} 30$, Novo Nordisk, Bagsvaerd, Denmark). The last two groups served as control and received $0.9 \%$ saline intraperitoneal injection for 1 or 3 days $(1 \mathrm{~mL} / \mathrm{kg})$. All rats at the end of experiment were healthy and no difference in food/ water consumption and body weight gain between experimental and control rats were observed. Three hours after the last injection, the animals were sacrificed using a decapitator (Harvard Apparatus, Holliston, MA, USA). The pancreas was carefully removed and divided into two portions. One portion of the pancreas was fixed in $4 \%$ paraformaldehyde for $24 \mathrm{~h}$, rinsed overnight in tap water, dehydrated in ethanol, cleared in xylene and embedded in paraffin. The other portion of the pancreas was fixed in $2.5 \%$ glutaraldehyde $(\mathrm{v} / \mathrm{v})$ in $0.1 \mathrm{M}$ Sørensen phosphate buffer (PB, pH 7.2). This portion was postfixed in $2 \%$ osmium tetroxide in the same buffer, routinely dehydrated using increasing concentrations of ethanol and embedded in Araldite (Fluka, Seeize, Germany).

\section{Stereological analyses of pancreatic acinar cells}

Semi-thin sections $(2 \mu \mathrm{m})$ were mounted on glass slides and stained with methylene blue and basic fuchsine. Stereological analyses of acinar cells were performed 
by point counting method, using Weibel's multi-purpose stereological grid M42. The volume of cytoplasm, nucleus and zymogen granules were analysed in 10 randomly chosen histological fields selected for each animal under a $100 \times$ oil-immersion objective. A standard stereological equation $V_{v}=P f / P t$ was used to calculate volume of cytoplasm, nucleus and granules in pancreatic acinar cells - the number of points (Pf) that coincided with the granules, nuclei or cytoplasm of the acinar cells, respectively, was divided by the total points falling on acinar cells (Pt) of a Weibel's multi-purpose test system [7, 32, 34]. All these analyses were performed on a Leica DMLB microscope (Leica Microsystems, Wetzlar, Germany).

\section{Fractal analyses}

Serial $5 \mu \mathrm{m}$ thick paraffin sections were mounted on glass slides and stained with haematoxylin and eosin. Sections were examined on a Leica DMLB microscope equipped with the digital camera Leica DFC295 (Leica Microsystems). From each stained section, photomicrographs of 10 random fields per exocrine pancreas were created. Acquired micrographs were in 24-bit tiff format, with image resolution of $2048 \times 1536$ pixels. Fractal analysis was performed using Image J software ( $\mathrm{NIH}$, Bethesda MD, USA) and its plugin FracLac. Fractal dimension and lacunarity calculations were performed on binarised and outlined images in Image J using the box counting method, as previously described [24]. The mean values were normalised with respect to appropriate control.

\section{Statistical analysis}

All data obtained were analysed by the software GraphPad Prism (GraphPad Software, San Diego, CA, USA). Normal distribution was tested by D'Agustino and Pearson's tests. If normality criteria were met, oneway ANOVA with post hoc Tukey's multiple comparison test was run; otherwise Kruskal-Wallis non-parametric test was run. The results are expressed as the mean \pm standard error of the mean (SEM) of obtained values with significances set at $p<0.05$.

\section{RESULTS}

In the insulin-treated rats, the histology of the exocrine pancreas was slightly changed comparing to control rats. In acute insulin-treated groups with an increase in insulin concentration, it is noted that the nuclei are larger, the granules are larger and are merge toward the lumen of the acinus secretory canals, and there is an increase in the space between the acinus itself, while the opposite effect occurs in chronically insulin-treated groups.

The mean fractal dimension of exocrine pancreas was significantly increased in both 0.4 IU $(1.008 \pm$ $\pm 0.001)$ and 4 IU $(1.001 \pm 0.001)$ acute insulintreated groups (Fig. 1A) compared to the control. In Figure $1 \mathrm{~B}$ were presented the mean values of lacunarity for the $4 \mathrm{IU}$ acute insulin-treated group $(0.897$ \pm 0.007 ) were significantly decreased compared to the control and $0.4 \mathrm{IU}$ acute insulin-treated group $(0.963 \pm 0.011)$. Therefore, it reflects a higher structural complexity (measured with fractal dimension) and lower structural heterogeneity (measured with lacunarity) of exocrine pancreas tissue.

On the other hand, the mean fractal dimension in chronic insulin-treated groups was decreased at $0.4 \mathrm{IU}$ (0.997 \pm 0.001$)$ compared to the corresponding control and was decreased compared to 4 IU (1.001 \pm \pm 0.001 ) (Fig. 1A). Chronic insulin treatment significantly increased the mean lacunarity in 0.4 IU (1.045 \pm 0.009$)$ compared to the control and was increased compared to 4 IU $(0.981 \pm 0.009)$ (Fig. 1B). The structural complexity of $0.4 \mathrm{IU}$ chronic insulin-treated group is lower compared to control, while 4 IU chronic insulin-treated group showed higher values compared to $0.4 \mathrm{IU}$ group. In contrast, the structural heterogeneity of $0.4 \mathrm{IU}$ chronic insulin-treated group is higher compared to control and 4 IU chronic insulin-treated group.

An increase in cytoplasm volume density of acinar cells in the acute $0.4 \mathrm{IU}$ insulin-treated group (1.208 \pm \pm 0.045 ) compared to the corresponding control and no significant difference compared to acute $4 \mathrm{IU}$ insulintreated group (1.078 \pm 0.037$)$ (Fig. 2A, 3). There was no significant difference between chronic insulin-treated groups (Fig. 2A). These results showed the low dose of insulin in acute insulin-treated groups significantly increased cytoplasmic volume density in acinar cells.

Changes in the granule volume density of acinar cells are presented in Figures $2 \mathrm{~B}$ and 3 . Analysing granules of acinar cells in acute insulin-treated groups, the $0.4 \mathrm{IU}$ insulin-treated group showed a significant decrease of granules density $(0.493 \pm 0.043)$ compared to the control. By contrast, the $4 \mathrm{IU}$ insulin-treated group (1.065 \pm 0.055$)$ showed an increase of granules density compared to the $0.4 \mathrm{IU}$ group (Fig. 2B). The mean volume density of granules in chronic insulin-treated groups was decreased in the 4 IU insulin-treated group $(0.815 \pm 0.028)$ compared to the corresponding control (Fig. 2B). 

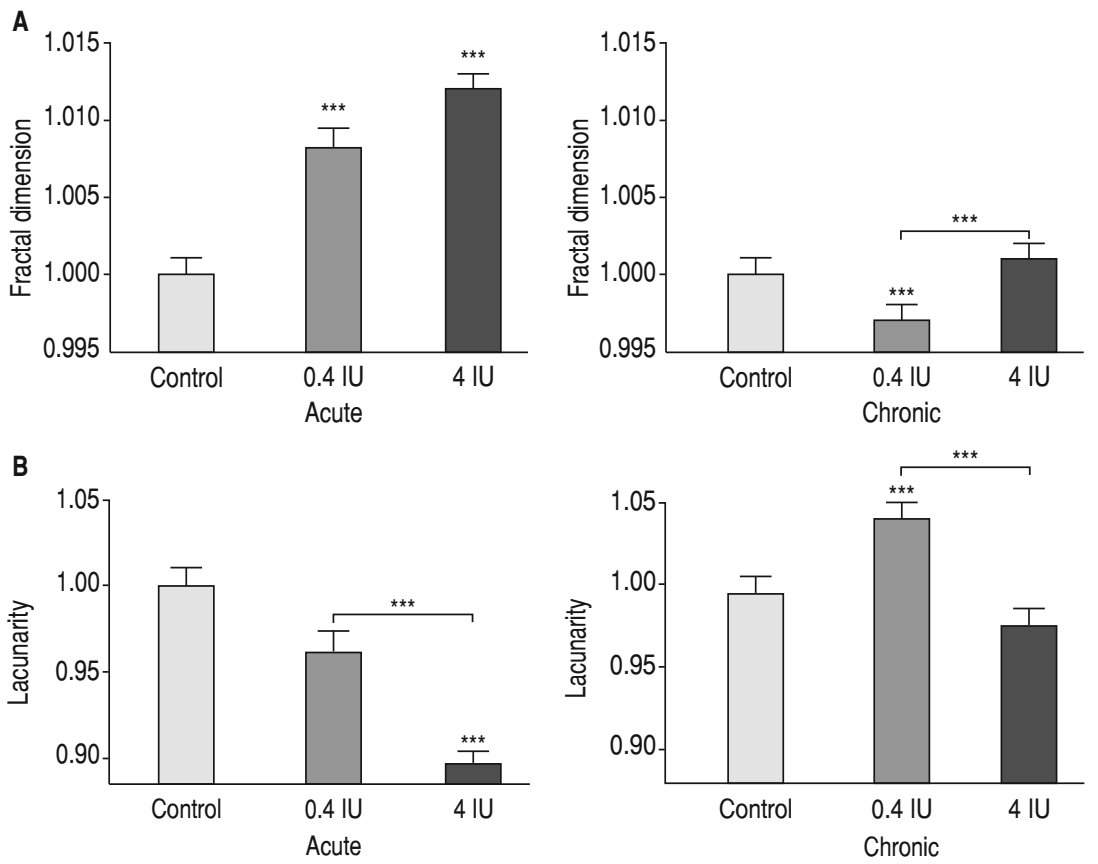

Figure 1. Fractal dimension (A) and lacunarity (B) of exocrine pancreas morphology in animals treated acutely or chronically with two different doses of insulin $(0.4 \mathrm{IU}$ and $4 \mathrm{IU})$ and controls. The values represent the mean \pm SEM, and ${ }^{* *} p<0.001$, as shown.

Nuclear volume density was not affected by insulin treatments (Fig. 2C).

\section{DISCUSSION}

Insulin, depending on dosage and treatment duration exerts different effects on the exocrine pancreas tissue architecture. We observed that different doses of insulin significantly change volume density of granules in the acinar cells. Therefore, we analysed effects of insulin (stimulation and inhibition) on enzyme synthesis and secretion, which reflects on the volume density of zymogen granules. Changes in volume density of zymogen granules are followed with changes in acinar cell structure, as well as in exocrine pancreas tissue.

It is well documented that insulin directly (via acinar insulin receptors) and indirectly (via cholecystokinin mechanism) regulates enzyme synthesis and secretion of the exocrine pancreas $[5,9,37]$. Morphological and haemodynamic studies indicate that insulin is necessary for normal acinar cell function. Insulin is a major regulator of pancreatic exocrine secretion and growth; many studies of insulin deficiency (diabetes mellitus) have shown exocrine tissue fibrosis and reduced response to hormonal stimulation. Taken together, these results clearly indicate that both exogenous and endogenous insulin can stimulate the acinar cells secretory process, which indicates an increase in granules and cytoplasm volume density and changes on morphological grounds $[4,25,32,33,38]$.

Fractal analyses rely on the morphological complexity and the intrinsic self-similarity that most natural shapes occurring in nature possess. Heterogeneity of the acinar cells plays an important role in any morphology change that can be detected with fractal analyses. All these changes may increase the level of detail during fractal analyses. The morphology change of exocrine pancreas tissue can be characterised with a fractal dimension that measures changing patterns with amplification and, therefore, can explain image complexity. Fractal dimension values range from 1 to 2 , with higher values representing greater complexity. Lacunarity measures image homogeneity from 0 to 1 , with a low value indicating homogeneity, while a high value indicates heterogeneity [19, 24]. Acute insulin treatment, independent of applied doses significantly increased fractal dimension of pancreas acini followed by decreased lacunarity. Chronic low dose decreased fractal dimension and increased lacunarity of pancreas acini, while high dose had the opposite effect. Therefore, parameters of fractal analysis provide reliable information about insulin effects on the morphological changes in the exocrine pancreas. These results are in line with reports of increasing enzyme synthesis in acinar cells after insulin treatment $[1,5,25]$. 

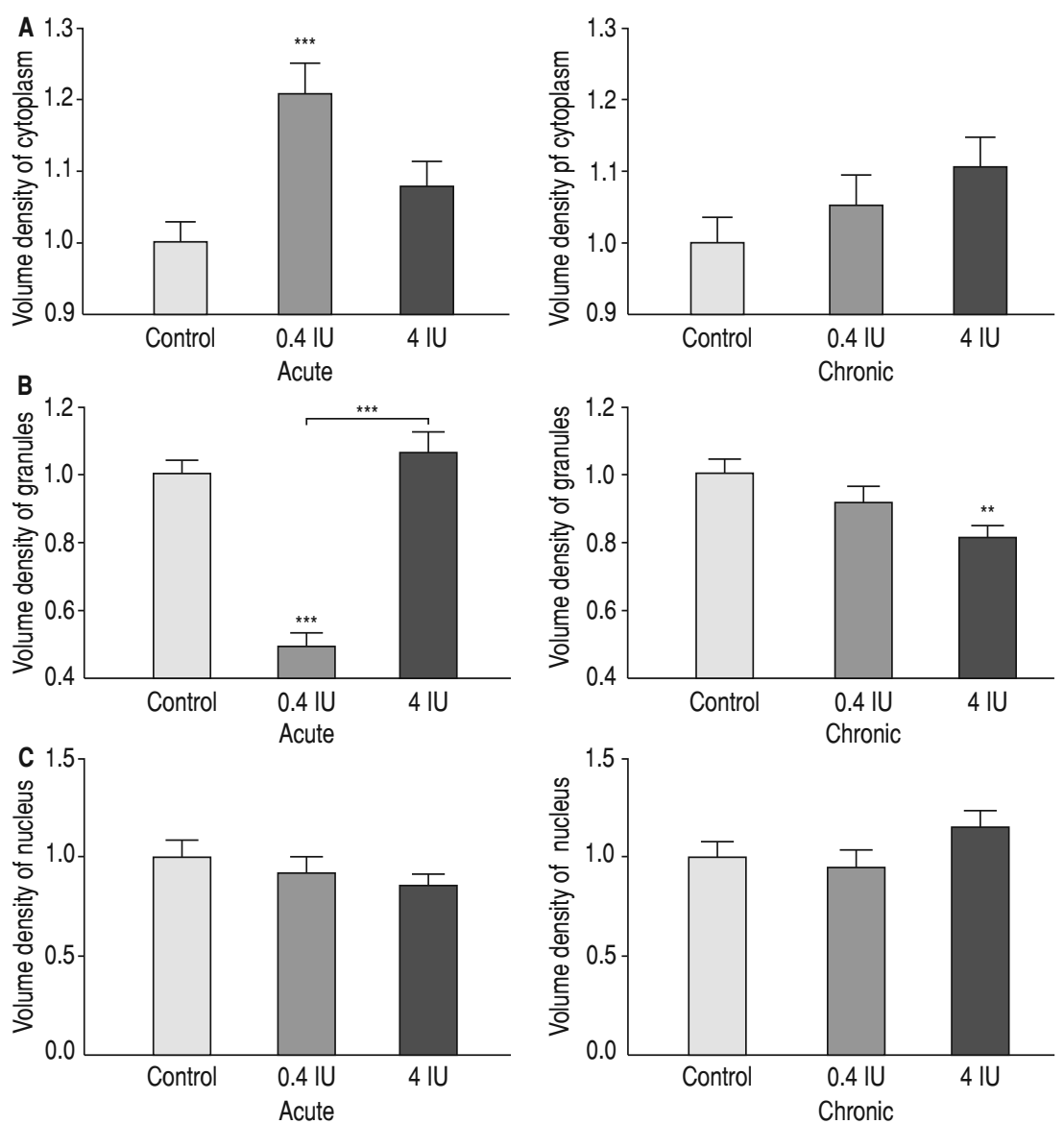

Figure 2. Volume density of cytoplasm (A), granules (B) and nucleus (C) of exocrine pancreas in animals treated acutely or chronically with two different doses of insulin (0.4 IU and $4 \mathrm{IU})$ and in controls. The values represent the mean \pm SEM, and ${ }^{* *} p<0.01,{ }^{* *} p<0.001$, as shown.

The complexity of the experimental system prevents an exact representation of the effects of insulin on pancreatic exocrine secretion. Previously published data indicates that insulin has long term effects on the regulation of the biosynthesis of pancreatic digestive enzymes and short term effects on the stimulation of pancreatic secretion $[4,7]$. The effect of exogenously administered insulin is expected to be followed by an increased rate of enzyme synthesis in the endoplasmic reticulum in pancreas acinar cells, which may have increased the volume density of cytoplasm as well as the volume density of granules. The stereological analyses performed in this study showed that acute low and chronic high dose of insulin significantly decreased granules and increased cytoplasmic volume density, whereas nucleus volume density showed slight and no significant changes. Our results greatly deviate from the expected and perhaps shed new light on the confrontation between endogenously synthesised and exogenously administered insulin. Exocrine acini were reported as enlarged with more zymogen granules near insulin-containing islets compared to insulin-negative islets. The impact of insulin via the portal system that conveys islet blood to acinar cells on the exocrine portion of pancreas is structurally and functionally well-orchestrated $[5,9,26]$. In vivo and in vitro studies suggest that isolated rat and mouse acini have insulin receptors, and after binding to its receptors, insulin regulates a number of functions including: sugar transport, protein synthesis, and the number of cholecystokinin receptors. These studies emphasize that the insulin-pancreatic acinar axis plays a major role in pancreatic function $[8,17,28]$.

Many recent studies concluded that fractal dimension can be implemented as prognostic factor for many carcinomas and successfully applied when analysing response to chemotherapy [13]. Fractal and stereological analysis helps us to gain a better understanding of the morphological changes in the exocrine pancreas. There are explanations for observed changes in structure of exocrine pancreas. From all measured parameters, volume density 

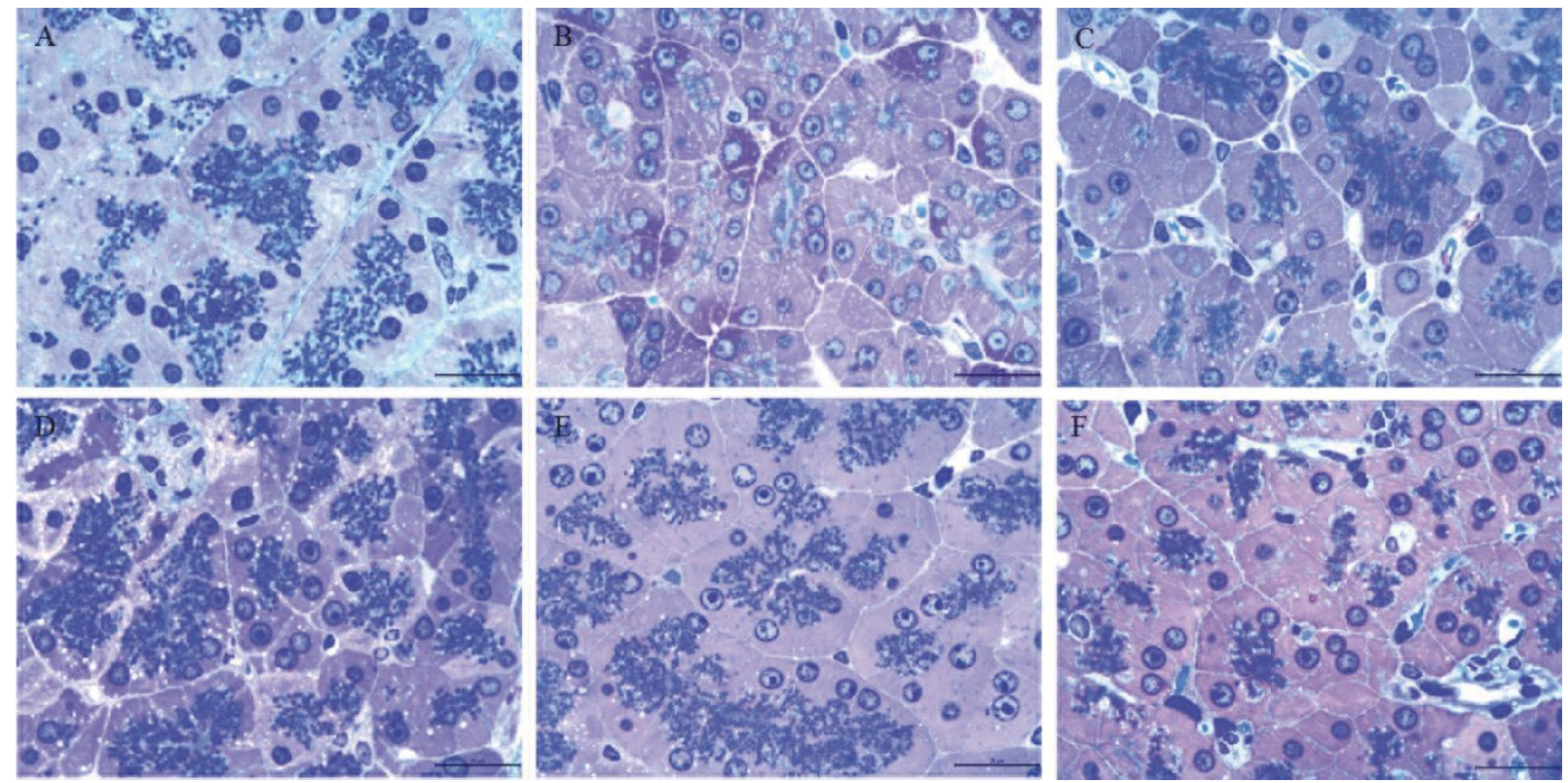

Figure 3. Light micrograph of exocrine pancreas from acute (A) and chronic (D) control and insulin-treated rats (B. 0.4 IU acute; C. 4 IU acute; E. 0.4 IU chronic; $\mathbf{F}$ 4 IU chronic). The most notable changes were observed in the granular compartment of acinar cells. Semi-fine section, methylene blue and basic fuchsine staining. Scale bar: $20 \mu \mathrm{m}$.

of granules was in line with fractal dimension. However, fractal dimension was not in line with lacunarity. It is possible that exogenously administered insulin changes enzyme synthesis in acinar cells, which reflects on increased volume density of zymogen granules. Increased or decreased volume density of zymogen granules and cytoplasm are followed by changes in acinar cell structure and in exocrine pancreas tissue. These results are in accordance with previously published data where it was found that in vivo insulin administration has a stimulating effect on amylase synthesis [3]. The exogenously administered insulin has the opposite effect on pancreatic fluid and bicarbonate secretion [16]. It is possible that insulin indirectly altered the shape and size of acinar lumens in which pancreatic enzymes are secreted. All these changes may increase the level of detail during binarisation and outline of the digital images; therefore, the values of fractal dimension and lacunarity. Any change in acinus shape could have a significant impact on the complexity of the exocrine pancreas tissue [18].

\section{CONCLUSIONS}

Our study revealed that insulin treatment induced structural changes in exocrine pancreas, suggesting a substantial role of insulin in maintaining its function. Additionally, we showed that fine architectural changes in acini could be detected by fractal analysis, and this method could be very useful as an alternative or an ad- dition to routine stereology. Further analyses of zymogen granules and acini ultrastructure will shed more light on the insulin influence on exocrine pancreas remodelling.

\section{Acknowledgements}

This work is supported by grant \#173055 from Serbian Ministry of Education, Science and Technological Development.

\section{REFERENCES}

1. Al-Mrabeh A, Hollingsworth KG, Steven S, et al. Morphology of the pancreas in type 2 diabetes: effect of weight loss with or without normalisation of insulin secretory capacity. Diabetologia. 2016; 59(8): 1753-1759, doi: 10.1007/s00125016-3984-6, indexed in Pubmed: 27179658.

2. Ashcroft FM, Rorsman P. Diabetes mellitus and the $\beta$ cell: the last ten years. Cell. 2012; 148(6): 1160-1171, doi: 10.1016/j. cell.2012.02.010, indexed in Pubmed: 22424227.

3. Aughsteen AA, Mohammed FI. Insulin enhances amylase and lipase activity in the pancreas of streptozotocin-diabetic rats. An in vivo study. Saudi Med J. 2002; 23(7): 838-844, indexed in Pubmed: 12174237.

4. Bani D, Magnani L, Sacchi TB, et al. The exocrine pancreas in patients with hyperinsulinemic hypoglycemia. A morphometrical and ultrastructural study. Int J Pancreatol. 1989; 5(3): 239-248, indexed in Pubmed: 2550561.

5. Barreto SG, Carati CJ, Toouli J, et al. The islet-acinar axis of the pancreas: more than just insulin. Am J Physiol Gastrointest Liver Physiol. 2010; 299(1): G10-G22, doi: 10.1152/ ajpgi.00077.2010, indexed in Pubmed: 20395539.

6. Bizzarri M, Giuliani A, Cucina A, et al. Fractal analysis in a systems biology approach to cancer. Semin Cancer Biol. 2011; 21(3): 175-182, doi: 10.1016/j.semcancer.2011.04.002, indexed in Pubmed: 21514387. 
7. Blanco-Molina A, González-Reyes JA, Torre-Cisneros J, et al. Effects of hypothyroidism on the ultrastructure of rat pancreatic acinar cells: a stereological analysis. Histol Histopathol. 1991; 6(1): 37-42, indexed in Pubmed: 1806054.

8. Campbell-Thompson M, Rodriguez-Calvo T, Battaglia M. Abnormalities of the exocrine pancreas in type 1 diabetes. Curr Diab Rep. 2015; 15(10): 79, doi: 10.1007/s11892-0150653-y, indexed in Pubmed: 26318606.

9. Cano DA, Hebrok M, Zenker M. Pancreatic development and disease. Gastroenterology. 2007; 132(2): 745-762, doi: 10.1053/j.gastro.2006.12.054, indexed in Pubmed: 17258745.

10. Cordain L, Eades MR, Eades MD. Hyperinsulinemic diseases of civilization: more than just Syndrome X. Comp Biochem Physiol A Mol Integr Physiol. 2003; 136(1): 95-112, indexed in Pubmed: 14527633.

11. Corkey BE. Banting lecture 2011: hyperinsulinemia: cause or consequence? Diabetes. 2012; 61(1): 4-13, doi: 10.2337/ db11-1483, indexed in Pubmed: 22187369.

12. Ferro DP, Falconi MA, Adam RL, et al. Fractal characteristics of May-Grünwald-Giemsa stained chromatin are independent prognostic factors for survival in multiple myeloma. PLoS One. 2011; 6(6): e20706, doi: 10.1371/journal.pone.0020706, indexed in Pubmed: 21698234.

13. Gheonea DI, Streba CT, Vere CC, et al. Diagnosis system for hepatocellular carcinoma based on fractal dimension of morphometric elements integrated in an artificial neural network. Biomed Res Int. 2014; 2014: 239706, doi: 10.1155/2014/239706, indexed in Pubmed: 25025042.

14. Gonzalez E, Flier E, Molle D, et al. Hyperinsulinemia leads to uncoupled insulin regulation of the GLUT4 glucose transporter and the FoxO1 transcription factor. Proc Natl Acad Sci U S A. 2011; 108(25): 10162-10167, doi: 10.1073/ pnas.1019268108, indexed in Pubmed: 21646544.

15. Gudea Al, Stefan AC. Histomorphometric, fractal and lacunarity comparative analysis of sheep (Ovis aries), goat (Capra hircus) and roe deer (Capreolus capreolus) compact bone samples. Folia Morphol. 2013; 72(3): 239-248, indexed in Pubmed: 24068686.

16. Hamamoto N, Ashizawa N, Niigaki M, et al. Morphological changes in the rat exocrine pancreas after pancreatic duct ligation. Histol Histopathol. 2002; 17(4): 1033-1041, doi: 10.14670/HH-17.1033, indexed in Pubmed: 12371130.

17. Hayden MR, Patel K, Habibi J, et al. Attenuation of endocrineexocrine pancreatic communication in type 2 diabetes: pancreatic extracellular matrix ultrastructural abnormalities. J Cardiometab Syndr. 2008; 3(4): 234-243, doi: 10.1111/j.15594572.2008.00024.x, indexed in Pubmed: 19040593.

18. Hotar V, Salac P. Surface evaluation by estimation of fractal dimension and statistical tools. Sci World J. 2014; 2014: 435935, doi: 10.1155/2014/435935, indexed in Pubmed: 25250380.

19. Jo J, Hörnblad A, Kilimnik G, et al. The fractal spatial distribution of pancreatic islets in three dimensions: a selfavoiding growth model. Phys Biol. 2013; 10(3): 036009, doi: 10.1088/1478-3975/10/3/036009, indexed in Pubmed: 23629025.

20. Johnson JD, Alejandro EU. Control of pancreatic beta-cell fate by insulin signaling: The sweet spot hypothesis. Cell Cycle. 2008; 7(10): 1343-1347, doi: 10.4161/cc.7.10.5865, indexed in Pubmed: 18418065.

21. Mehran AE, Templeman NM, Brigidi GS, et al. Hyperinsulinemia drives diet-induced obesity independently of brain insulin production. Cell Metab. 2012; 16(6): 723-737, doi: 10.1016/j. cmet.2012.10.019, indexed in Pubmed: 23217255.
22. Metze K. Fractal dimension of chromatin: potential molecular diagnostic applications for cancer prognosis. Expert Rev Mol Diagn. 2013; 13(7): 719-735, doi: 10.1586/14737159.2013. 828889, indexed in Pubmed: 24063399.

23. Motta PM, Macchiarelli G, Nottola SA, et al. Histology of the exocrine pancreas. Microsc Res Tech. 1997; 37(5-6): 384-398, doi: 10.1002/(SICI)1097-0029(19970601)37:5/6<384::AIDJEMT3 > 3.0.CO;2-E, indexed in Pubmed: 9220418.

24. Pantic I, Nesic D, Stevanovic $D$, et al. Effects of ghrelin on the structural complexity of exocrine pancreas tissue architecture. Microsc Microanal. 2013; 19(3): 553-558, doi: 10.1017/ S1431927613000524, indexed in Pubmed: 23628379.

25. Pap A. Effects of insulin and glucose metabolism on pancreatic exocrine function. Int J Diabetes Metab. 2004; 12: 30-34.

26. Piciucchi M, Capurso G, Archibugi L, et al. Exocrine pancreatic insufficiency in diabetic patients: prevalence, mechanisms, and treatment. Int J Endocrinol. 2015; 2015: 595649, doi: 10.1155/2015/595649, indexed in Pubmed: 25892991.

27. Rhodes $\mathrm{C}$, White MF. Molecular insights into insulin action and secretion. Eur J Clin Invest. 2002; 32 Suppl 3: 3-13, indexed in Pubmed: 12028370.

28. Saito A, Williams JA, Kanno T. Potentiation of cholecystokinin-induced exocrine secretion by both exogenous and endogenous insulin in isolated and perfused rat pancreata. J Clin Invest. 1980; 65(4): 777-782, doi: 10.1172/JCl109727, indexed in Pubmed: 6987265.

29. Samuel VT, Shulman GI. Mechanisms for insulin resistance: common threads and missing links. Cell. 2012; 148(5): 852-871, doi: 10.1016/j.cell.2012.02.017, indexed in Pubmed: 22385956.

30. Shanik MH, Xu Y, Skrha J, et al. Insulin resistance and hyperinsulinemia: is hyperinsulinemia the cart or the horse? Diabetes Care. 2008; 31 Suppl 2: S262-S268, doi: 10.2337/dc08-s264, indexed in Pubmed: 18227495.

31. Sirri R, Bianco C, De Vico G, et al. Proliferation, apoptosis, and fractal dimension analysis for the quantification of intestinal trophism in sole (Solea solea) fed mussel meal diets. BMC Vet Res. 2014; 10: 148, doi: 10.1186/1746-6148-10-148, indexed in Pubmed: 24997003.

32. Slavin BG, Zarow $\mathrm{C}$, Warden $\mathrm{CH}$, et al. Histological, immunocytochemical, and morphometrical analyses of pancreatic islets in the BSB mouse model of obesity. Anat Rec (Hoboken). 2010; 293(1): 108-116, doi: 10.1002/ar.21019, indexed in Pubmed: 19798700

33. Taga R, Faverão MR, Cestari TM, et al. Morphometric dimensions of Syrian golden hamster pancreas of both sexes. Okajimas Folia Anat Jpn. 1999; 76(1): 41-46, indexed in Pubmed: 10409844.

34. Weibel ER, Kistler GS, Scherle WF. Practical stereological methods for morphometric cytology. J Cell Biol. 1966; 30(1): 23-38, indexed in Pubmed: 5338131.

35. West BJ. Fractal physiology and the fractional calculus: a perspective. Front Physiol. 2010; 1: 12, doi: 10.3389/ fphys.2010.00012, indexed in Pubmed: 21423355.

36. Wilcox G. Insulin and insulin resistance. Clin Biochem Rev. 2005; 26(2): 19-39.

37. Williams JA, Goldfine ID. The insulin-pancreatic acinar axis. Diabetes. 1985; 34(10): 980-986, indexed in Pubmed: 2412919.

38. Williams JA. Regulation of acinar cell function in the pancreas. Curr Opin Gastroenterol. 2010; 26(5): 478-483, doi: 10.1097/ MOG.0b013e32833d11c6, indexed in Pubmed: 20625287.

39. Yang $X$, Mei S, Gu H, et al. Exposure to excess insulin (glargine) induces type 2 diabetes mellitus in mice fed on a chow diet. J Endocrinol. 2014; 221(3): 469-480, doi: 10.1530/JOE-140117, indexed in Pubmed: 24741073. 